\title{
Clinical-course of alcohol related disorders among male and female patients seeking help from psychiatric service of a tertiary-care-hospital in eastern nepal
}

\begin{abstract}
Background: Gender difference in clinical course of alcohol related disorders (ARD) may reveal different priorities.

Objective: To compare the variables related to clinical course of alcohol related disorders in male and female patients seeking help from department of psychiatry of a tertiary care hospital in eastern Nepal.

Method: This is a hospital based study among consecutive alcohol related disorder (the ICD 10) patients coming in contact with the investigator. A semi-structured proforma was prepared to document socio-demographic profile, clinical course correlates and relevant information. Clinical course related major variables were compared between male and female patients.

Results: Seventy five male and 75 female patients with alcohol related disorder were enrolled. Average (minimum and maximum) ages of male and female patients at psychiatric consultation were $37.63(17,84)$ and $40.69(18,72)$ years respectively. Males visited psychiatric service after $11.30(0.1,40)$ years and females $7.11(0.1$, 40) years of problem drinking. Onset of problem drinking was gradual and pattern of use continuous in most subjects of both genders. More female patients reported stress than males.

Conclusion: Male Nepalese patients with ARDs seek psychiatric service later than females though the duration since first alcohol use was similar in both the genders. Onset of the problem use was gradual and pattern of alcohol use continuous in both genders. The problem was associated with stressors in more females.
\end{abstract}

Volume 3 Issue 2 - 2017

\section{Shakya DR}

Department of Psychiatry, BP Koirala Institute of Health Sciences, Nepal

Correspondence: Dhana Ratna Shakya,Additional professor, Department of Psychiatry, BP Koirala Institute of Health Sciences, Dharan, Ghopa-18, Sunsari, Koshi, Nepal, Tel 977-025525555, Ext 5334, 5347,Email drdhanashakya@yahoo.com

Received: October 30, 2016 | Published: March 07, 2017
Abbreviations: ADS, alcohol dependence syndrome; ARD, alcohol related disorder; AUD, alcohol use disorders; BPKIHS, bp koirala institute of health sciences; DSM, diagnostic and statistical manual of mental disorders; HUA, harmful use of alcohol; ICD 10 , the international classifications of diseases 10th edition; SPSS, statistical package for social studies

\section{Introduction}

Alcohol related disorder (ARD) is one of the common disorders worldwide ${ }^{1-2}$ and in Nepal, ${ }^{3}$ including eastern Nepal. ${ }^{4}$ It is reported as common among both male and female patients in BP Koirala Institute of Health Sciences (BPKIHS). ${ }^{5-8}$ There are reports from other parts about sex-wise differences in various aspects of alcohol use and ARD, and such gender differences may reveal different priorities. ${ }^{8-11}$ Some of these biological, psychological and social factors and correlates deemed associated with clinical course of this disorder might be true for Nepalese context as well, though many of them might not. Hence, this warrants a study also in Nepalese context.

There have been some studies about different facets of ARD in this

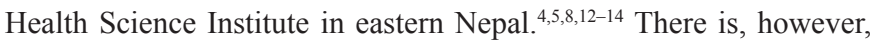
little information about gender comparison of clinical course of
ARD from this part of Nepal. In Nepalese context, this study was conducted to find out similarities and differences in clinical course correlates between male and female patients coming into the contact of psychiatric service of this teaching institute in eastern Nepal.

\section{Materials and methods}

This is a hospital based study conducted among consecutive alcohol related disorder patients coming into the contact of the investigator in the Department of Psychiatry of a teaching institute in eastern Nepal within the study period starting from July, 2006. A total of 150 subjects were enrolled, including 75 male and 75 females. The diagnoses were made as per the 'International Classification of Diseases, 10th edition' (ICD-10) criteria [including all related categories, i.e. Alcohol intoxication, Harmful use, Alcohol dependence syndrome (ADS), Alcohol withdrawal state, etc. ${ }^{15}$

Informed consent was collected from the subjects and significant care-givers (when not possible from the patient). Strict confidentiality of information was maintained and the results would be utilized for the appropriate management of the concerned cases and similar cases in general. This study was approved and presented in the 'institute scientific forum'. 
All the consenting consecutive patients with the ICD-10 diagnosis of 'Alcohol related disorders' (with no debilitating medical conditions/ complications making them unable to participate) were enrolled in this study.

A semi structured proforma was prepared to collect and document the information about various facets of the clinical course along with: socio-demographic profile, referral sources, presenting complaints, characteristic features of various ARDs, other related important clinical information and ARD diagnosis. In all subjects; an intensive exploration was made to ascertain the variables related with the clinical course, i.e. duration of alcohol use, duration of problematic alcohol use, onset of problem, type or pattern of use. The reason for delay in seeking help was explored by directly asking the patients and or their attending family member and assessing overall clinical information.

Data were entered into a computer and clinical course related major variables were compared between genders using 'Statistical Package for Social Studies' (SPSS 16.0)-software.

\section{Results and discussion}

\section{Results}

We enrolled 150 subjects, 75 female and 75 male in this study to emphasize gender-wise comparison.

Table I Socio-demographic variables- Ethnicity, Age, Marital Status, Education and Residential settings

\begin{tabular}{|c|c|c|c|c|}
\hline Caste-ethnicity & Female (\%) & Male (\%) & Total (\%) & $\mathrm{p}$-value (x2) \\
\hline Upper Hill & $4(5.3)$ & $23(30.6)$ & $27(18.0)$ & \\
\hline Terai & $3(4.0)$ & $5(6.7)$ & $8(5.3)$ & \\
\hline Relatively advanced Janajati & $10(13.3)$ & $5(6.7)$ & $15(10.0)$ & \\
\hline Disadvantaged Hill Janajati & $53(70.7)$ & $35(46.7)$ & $88(58.7)$ & \\
\hline Hill Dalit & $5(6.7)$ & $7(9.3)$ & $12(8.0)$ & 0.001 \\
\hline Age groups (yrs.) & Female (\%) & Male (\%) & Total (\%) & \\
\hline$<30$ & $10(13.3)$ & I5 (20.0) & $25(16.7)$ & \\
\hline $30-39$ & $26(34.7)$ & $29(38.7)$ & $55(36.7)$ & \\
\hline $40-49$ & $23(30.7)$ & $21(28.0)$ & $44(29.3)$ & \\
\hline$\geq 50$ & $16(21.3)$ & $10(13.3)$ & $26(17.3)$ & 0.451 \\
\hline Marital status & Female (\%) & Male (\%) & Total (\%) & \\
\hline Married & $61(81.3)$ & $64(85.3)$ & $125(83.3)$ & \\
\hline Single/ Separate/Widow & 14 (I8.7) & II (I4.7) & $25(16.7)$ & 0.511 \\
\hline Educational status & Female (\%) & Male (\%) & Total (\%) & \\
\hline Illiterate & $42(56.0)$ & $9(12.0)$ & $5 \mathrm{I}(34.0)$ & \\
\hline $\mathrm{I}-\mathrm{VII}$ & I8 (24.0) & $24(32.0)$ & $42(28.0)$ & \\
\hline VIII - SLC & $8(I 0.7)$ & $27(36.0)$ & $35(23.3)$ & \\
\hline Intermediate \& High & $7(9.3)$ & $15(20.0)$ & $22(14.7)$ & 0.001 \\
\hline Residential settings & Female (\%) & Male (\%) & Total (\%) & \\
\hline Nearby/ Dharan & $30(40.0)$ & $35(46.7)$ & $65(43.3)$ & \\
\hline Accessible by motor road & $28(37.3)$ & $35(46.7)$ & $63(42.0)$ & \\
\hline Far/ difficult & 17 (22.7) & $5(6.6)$ & $22(14.7)$ & \\
\hline Total & $75(100)$ & $75(100)$ & $150(100)$ & 0.021 \\
\hline
\end{tabular}

Citation: Shakya DR. Clinical-course of alcohol related disorders among male and female patients seeking help from psychiatric service of a tertiary-carehospital in eastern nepal. MOJ Addict Med Ther. 20I7;3(2):25-3I. DOI: 10.15406/mojamt.2017.03.00028
Male representation was more among Upper Hill castes (e.g. Brahmin, Chhetri) and slight more among Terai and Hill Dalit. Female was more among Relatively advanced Janajati (e.g. Gurung, Newar) and Disadvantaged Hill Janajati (e.g. Limbu, Tamang, Rai). The caste difference between genders was statistically significant $(\mathrm{p}=0.001)$.

A great majority of the subjects were married. Status of separation and widowhood was more among females. However, Single, separated and widow had to be combined together because of small figures for the calculation of $\mathrm{p}$-value which was not statistically significant $(\mathrm{p}=0.511)$.

Average (minimum and maximum) ages of male and female patients at psychiatric consultation were $37.63(17,84)$ and 40.69 $(18,72)$ years respectively. Age groups (30-39) and (40-49) had the largest number of subjects. Gender-wise Age difference was not statistically significant $(\mathrm{p}=0.451)$.

More males were educated than females among problem drinkers. Difference of educational status was highly statistically significant $(\mathrm{p}=0.001)$.

A great majority of cases were from nearby and accessible places. More females were from far places than males. There was a statistically significant difference between genders $(p=0.021)$ (Table $1)$. 
Average duration since first alcohol use was $21.67(0.1,69)$ for male and $22.00(1,55)$ years for females. The duration of alcohol use and onset of alcohol problem were not statistically different among genders $(\mathrm{p}=0.134$ and $\mathrm{p}=0.112)$. Pattern was also not significantly different $(\mathrm{p}=0.497)$. Total duration of problem drink was overall 7.11 $(0.1,40)$ among females and $11.30(0.1,40)$ years among males, which was statistically different $(\mathrm{p}=0.008)$. More females had perceived stressor, the difference being significant $(\mathrm{p}=0.001)$ (Table 2). More female patients came on themselves and were referred by specialty clinics (e.g. Internal medicine), and more males with family, relatives and referred by department of Emergency and family medicine $(\mathrm{p}=0.005)$ (Table 3$)$.

Table 2 Gender distribution of Duration, Onset and Pattern of use; and Duration of problem use and stress status

\begin{tabular}{lllll}
\hline Total duration of use (yrs.) & Female (\%) & Male (\%) & Total (\%) & p-value (x2) \\
\hline$<1-9$ & $14(18.7)$ & $7(9.3)$ & $21(14.0)$ & \\
$19-$ Oct & $19(25.3)$ & $25(33.3)$ & $44(29.3)$ & \\
$20-29$ & $16(21.3)$ & $24(32.0)$ & $40(26.7)$ & \\
$30-39$ & $15(20.0)$ & $14(18.7)$ & $29(19.3)$ & \\
$\geq 40$ & $11(14.7)$ & $5(6.7)$ & $16(10.7)$ & 0.134 \\
\hline Onset of problem use & & & & \\
\hline Gradual/ insidious & 74 & 74 & 148 & \\
Sudden/ abrupt & 1 & 1 & 2 & \\
Pattern of use & & & & \\
Episodic/ binge & $10(13.3)$ & $13(17.3)$ & $23(15.3)$ & \\
Continuous/ daily & $65(86.7)$ & $62(82.7)$ & $127(84.7)$ & 0.497 \\
\hline Duration of problem use (yrs.) & & & & \\
\hline$<5$ & $31(41.3)$ & $19(25.3)$ & $50(33.3)$ & \\
5-Sep & $20(26.7)$ & $14(18.7)$ & $34(22.7)$ & \\
I4-Oct & $17(22.7)$ & $20(26.7)$ & $37(24.7)$ & \\
$\geq 15$ & $7(9.3)$ & $22(29.3)$ & $29(19.3)$ & 0.008 \\
\hline Status of perceived stressor & & & & \\
\hline Present & $60(80.0)$ & $41(54.7)$ & $101(76.3)$ & \\
Absent & $15(20.0)$ & $34(45.3)$ & $49(23.7)$ & 0.001 \\
\hline
\end{tabular}

Table 3 Gender distribution of Referral sources*

\begin{tabular}{lllll}
\hline Source of immediate referral & Female (\%) & Male (\%) & Total (\%) & p-value (x2) \\
\hline Patient self & $15(20.0)$ & $8(10.7)$ & $23(15.3)$ & \\
Family member & $20(26.7)$ & $31(4 I .3)$ & $5 I(34.0)$ & \\
Relative, friend, neighbor, authority & $4(5.3)$ & $14(18.7)$ & $18(12.0)$ & \\
Alternative/ Traditional & $4(5.3)$ & $2(2.7)$ & $6(4.0)$ & \\
Emergency, General medicine & $8(10.7)$ & $10(13.3)$ & $18(12.0)$ & \\
Specialty clinics (Medical/ Surgical) & $24(32.0)$ & $10(13.3)$ & $34(22.7)$ & 0.005
\end{tabular}

Among the ICD-10 symptom criteria for Alcohol dependence syndrome (ADS), physiological withdrawal and persisting use despite harm were statistically more among males than females $(\mathrm{p}=0.051$ and $\mathrm{p}=0.051)$ (Table 4).

Anxiety and suicidality were significantly more as presenting complaint among females who came more to quit it as well. Perceptual disturbance such as hallucination was statistically more among males (Table 5).
More females presented with harmful use than males whereas more males in withdrawal state, uncomplicated and with delirium (Table 6).

Lack of realization of alcohol use as a problem and denial were more among males as reasons for delay in seeking professional help. More females were delayed because of drinking as a coping or because they felt some positive effect of alcohol. More male subjects were being treated elsewhere for the problem though it was not statistically significant (Table 7). 
Table 4 Gender distribution of ICDI0 Symptom criteria for ARD*

\begin{tabular}{lllll}
\hline ICD- I O ADS symptom criteria & Female (\%) & Male (\%) & Total (\%) & p-value (x2) \\
\hline Withdrawal & $53(70.7)$ & $63(84.0)$ & $116(77.3)$ & 0.05 I (S) \\
Persisting use despite harm & $53(70.7)$ & $63(84.0)$ & $116(77.3)$ & $0.05 I(S)$ \\
Tolerance & $65(86.7)$ & $67(89.3)$ & $132(88.0)$ & $0.615(\mathrm{NS})$ \\
Neglect of other interests & $4 \mathrm{I}(54.7)$ & $39(52.0)$ & $80(53.3)$ & 0.743 (NS) \\
Difficult to control & $56(74.7)$ & $6 \mathrm{I}(81.3)$ & $117(78.0)$ & 0.324 (NS) \\
Compulsion to drink & $44(58.7)$ & $49(65.3)$ & $93(62.0)$ & 0.400 (NS) \\
Harmful use & $13(17.3)$ & $6(8.0)$ & $19(12.7)$ & 0.086 (NS) \\
\hline
\end{tabular}

Table 5 Gender distribution of Presenting complaint*

\begin{tabular}{lllll}
\hline Presenting complaint & Female (\%) & Male (\%) & Total (\%) & p-value (x2) \\
\hline Behavioral problem & $20(26.7)$ & $26(34.7)$ & $46(30.7)$ & 0.288 (NS) \\
Mood disturbance & $18(24.0)$ & $10(13.3)$ & $28(18.7)$ & 0.094 (NS) \\
Anxiety & $49(65.3)$ & $31(41.3)$ & $80(53.3)$ & $0.003(\mathrm{~S})$ \\
Thought, speech & $12(16.0)$ & $21(28.0)$ & $33(22.0)$ & $0.076(\mathrm{NS})$ \\
Perceptual disturbance & $10(13.3)$ & $25(33.3)$ & $35(23.3)$ & $0.004(\mathrm{~S})$ \\
Altered consciousness & $20(26.7)$ & $23(30.7)$ & $43(28.7)$ & $0.588(\mathrm{NS})$ \\
Suicidal tendency & $16(21.3)$ & $6(8.0)$ & $22(14.7)$ & $0.021(\mathrm{~S})$ \\
Physical complaints & $19(25.3)$ & $13(17.3)$ & $32(21.3)$ & $0.232(\mathrm{NS})$ \\
Somatic sleep/symptom & $62(82.7)$ & $56(74.7)$ & $118(78.7)$ & $0.232(\mathrm{NS})$ \\
Other complaints & $29(38.7)$ & $8(10.7)$ & $37(24.7)$ & 0.001 (S) \\
Quit alcohol use & $19(25.3)$ & $4(5.3)$ & $23(15.3)$ & 0.001 (S)\#
\end{tabular}

Table 6 Gender distribution of ICD I0 AUD

\begin{tabular}{|c|c|c|c|c|}
\hline ICD I0 AUD diagnosis & Female (\%) & Male (\%) & Total (\%) & p-value (x2) \\
\hline Harmful use & $15(20.0)$ & $5(6.7)$ & $20(13.3)$ & 0.08 \\
\hline ADS (no withdrawal) & $16(21.3)$ & II (I4.7) & $27(18.0)$ & \\
\hline ADS, withdrawal & $23(30.7)$ & $28(37.3)$ & $51(34.0)$ & \\
\hline ADS, withdrawal complicated & $14(18.7)$ & $21(28.0)$ & $35(23.3)$ & \\
\hline ADS, other (induced/ Amnestic syndrome) & $7(9.3)$ & $10(13.3)$ & $17(11.3)$ & \\
\hline
\end{tabular}

Table 7 Gender distribution of Reason for treatment delay*

\begin{tabular}{|c|c|c|c|c|}
\hline Reason for delay & Female (\%) & Male (\%) & Total (\%) & p-value (x2) \\
\hline Denial/ Ignorance & $35(46.7)$ & $59(78.7)$ & $94(62.7)$ & $0.001(S)$ \\
\hline Positive effect / Coping & $14(18.7)$ & 0 & $14(18.7)$ & $0.001(\mathrm{~S}) \#$ \\
\hline Treated in other place & $5(6.7)$ & $12(16.0)$ & $17(11.3)$ & $0.07 I$ (NS)\# \\
\hline Adverse factors & $4(5.3)$ & $4(5.3)$ & $8(5.3)$ & $\mathrm{I} .000$ (NS)\# \\
\hline $\begin{array}{l}\text { Other (withdrawal, co-morbidity, } \\
\text { negative view to treatment) }\end{array}$ & II (I4.7) & $7(9.3)$ & $18(12.0)$ & 0.315 (NS) \\
\hline
\end{tabular}

* Multiple-response question

\# Fisher's Exact Test 


\section{Discussion}

Alcohol use and alcohol problems are prevalent in community worldwide. ${ }^{1,2}$ Dharan, a city in eastern Nepal has long been reported with high alcohol problem prevalence in community, both among males $^{16}$ and females. ${ }^{17}$ Alcohol problem has strikingly been found as the most common diagnostic factor for psychiatric emergencies in BPKIHS, ${ }^{6}$ the study site. Alcohol use and ARD are reported to be more among males than among females worldwide in all times across all age groups and places ${ }^{1,18,19}$ though some variation is seen in some local contexts. Such contextual and local differences guide for different forms and levels of management and prevention. ${ }^{11}$ In this pretext, current study intends to document and, more precisely, to compare between the genders the different variables related to the course of alcohol related disorders in this part of Nepal.

'Clinical course' is the path taken by a clinical problem, operationally defined in this study as beginning from the onset of problematic alcohol use to the point of the study enrolment. We explored in all subjects the following correlates as related to the clinical course of the ARD: onset, duration of alcohol use, duration of problematic use, pattern of use, stressor status, referral source, presenting complaints, Alcohol related disorder (ARD) features, Alcohol related disorder (ARD) ICD-10 diagnosis, reason for delay in help seeking. Our intension is to document them and explore the modifiable areas where we can intervene with palpable and positive effect. We hope the understanding of these salient features will help devise necessary strategies to combat this common problem.

While talking about the course of a clinical problem, turning point would be the consideration of 'onset', i.e. the point of transition from a pre-morbid to a discernible problem state/ disorder. Since the use of substance encompasses a range of behaviors possibly normal, i.e. social, controlled, sensible drinking to abnormal, i.e. heavy, chronic, risky drinking (drinking in risky situations, e.g. drunk driving) and uncontrolled and pathological drinking; the onset is defined in this study operationally as onset of ARD or problem drinking. ARD consists of a wide range of conditions both in the ICD-10 and DSM classifications and we adopted the ICD-10 classification in this study Alcohol use disorders (AUD)-Acute Intoxication, Harmful use, ADS and Alcohol Induced disorders. ${ }^{15}$ Theoretically; Intoxication and Harmful Use of Alcohol (HUA) can be acute or abrupt in onset, though the substance behaviors and related disorders usually evolve gradually. But people with problem drinking would present to clinical setting only when there is a significant problem, mainly health complications though at times might be brought by police authority while found inebriated (even then psychiatric consultation may not be sought). Hence, the onset regarding ARD would be, as usually described as gradual or insidious in an observation in psychiatric service setting. ${ }^{5-18}$ For both the genders, the onset was insidious or gradual, with no gender difference in this study $(\mathrm{p}=0.112)$. The pattern of the drinking was continuous or daily for most of the cases, both males and females statistically not different $(p=0.497)$.

We documented both the duration since the first use and problem drinking. For most number of subjects, the duration since their first use falls in (10-29) years for both the genders. $67(0.1,69)$ for male and $22.00(1,55)$ years for females], with no overall significant statistical difference $(\mathrm{p}=0.134)$. There were more females with duration less than 10 years and more than 40 years, however. This observation seems realistic for a setting where alcohol use is socio- culturally sanctioned and is prevalent in community. ${ }^{16-17}$ However, finding about the duration of problem drinking was striking one, it's statistically significant between the genders $(\mathrm{p}=0.008)$. Females have less number of years $7.11(0.1,40)$ and males have more $11.30(0.1,40)$ years overall as duration of problem drinking. This finding keeps in line with the understanding that females usually develop problems and complications with alcohol sooner than males. ${ }^{18}$

The report of stressors associated with the predisposition, precipitation and perpetuation of the alcohol problem should be the area of separate study and discussion. However, we tried to document the status of perceived stressor among the subjects. More females reported the presence of stressor as significant in relation to their problem drinking $(\mathrm{p}=0.001)$. This keeps in tune with our findings of other study regarding the circumstances of first alcohol use. ${ }^{20}$

More males were brought to psychiatric service by family members, relatives, neighbours and were referred by Department of emergency and Family medicine, indicating that they were brought in more severe state or their alcohol problem was perceived more acutely. More females had one or other problems and more of them visited the service on their own, visiting other specialties including Internal medicine and were referred by them to the psychiatric service.

Five of the six ICD-10 Alcohol Dependence Syndrome (ADS) symptoms were more found among male subjects except neglect of other interests, and among them; physiological withdrawal and continued use despite harm were seen significantly more among males. Though not statistically significant, Harmful Use of Alcohol was seen more among female subjects seeking help here. This needs more intensive exploration about the internal consistency of the features here. Our observation possibly indicates that despite these features of problem drinking, males seek help later as evidenced also by the longer duration of problem drinking by the time of psychiatric consultation in this study. Here, one point is noteworthy that the feature 'tolerance' exceeds the number of subjects with Alcohol Dependence Syndrome (ADS), indicating that even among other categories of $\mathrm{ARD}$, this feature has been documented in this study. Presenting complaints related to abnormal behavior, thoughts, perception, consciousness were reported more among males whereas more females had mood, anxiety, suicidal tendencies, physical and somatic complaints. Perceptual problem was seen remarkably more among males, and anxiety and suicidal tendency among females. More females expressed at the time of psychiatric consultation their concern about their habit of drinking which they wished to quit. The pattern of presenting complaints and help seeking pattern is complex issue and is influenced by existing stigma. The pattern of presenting complaints in this study somewhat keeps with the literature about females with their sociability and more expressiveness of their problem to other people including clinician. ${ }^{21}$ At the same time, males are reported more to disclose their alcohol problems.

By the time of psychiatric consultation, majority of both genders had at least Alcohol Dependence Syndrome (ADS) (of the ICD-10 ARDs in severity range). More females came with Harmful Use of Alcohol, less severe than ADS when consulting a psychiatrist. Some females needed to be brought while in active use and one female had features of Amnesic syndrome. More males had withdrawal and Delirium Tremens. These findings again indicate that this problem is prevalent among both the genders. ${ }^{16-17}$ More specific exploration is required for definite and in-depth understanding. 
Whereas males presented later to the psychiatric service than females indicated by the duration of problem drinking, the reasons were more or less similar among both the genders, e.g. lack of realization as a problem despite some specific differences, e.g. more males reported ignorance, expressed denial of the problem and more females pointed out some of its beneficial effects.

We had some limitations in this study. First, the sample was biased as it studied only the patients seeking help from psychiatry department of this institute. Second, recall bias could not be ruled out about the report of their past facts, e.g. onset, duration. Third, as pointed out earlier, despite of male preponderance of alcohol problem in community setting, we enrolled equal number of male and female samples to emphasize gender representation which might not allow the result to be applicable to community setting. However, these limitations do not make difference for its objective. And, the findings are expected to be useful in:

1. Guiding the clinical management of this common problem

2. Furthering in-depth and community based studies to better understand this problem

3. Policy making and planning for preventive programs.

Here, the most important aspect is to emphasize on modifiable factors of alcohol problem and to encourage the needful strategies. And most important but long term step for positive change would be public awareness regarding ARD in different levels (individual, family, school and community) through various effective programs.

\section{Conclusion}

Duration and pattern of alcohol use and onset of problem were similar but total duration of problem drink differed in male and female patients with ARD. Presence of perceived stressor was more among females. More female patients came themselves and referred by specialty clinics, e.g. Internal medicine, and more male by family, relative and referred by Emergency and family medicine department. Among the ICD-10 criteria for Alcohol dependence, physiological withdrawal and persisting use despite harm were seen more among males. Anxiety and suicidality were significantly more as presenting complaint among females who came more to quit alcohol drinking as well. Perceptual disturbance was statistically more among males. More females presented with Harmful use of alcohol than males, and more males in withdrawal state, uncomplicated and with delirium. Lack of realization of alcohol use as a problem and denial were more among males as reasons for delay in seeking professional help. More females delayed because of their use of alcohol drinking as coping.

Male representation was more among Upper Hill castes (e.g. Brahmin, Chhetri) and slight more among Terai and Hill Dalit. Female was more among Relatively advanced Janajati (e.g. Gurung, Newar) and Disadvantaged Hill Janajati (e.g. Limbu, Tamang, Rai). Gender age difference was not statistically significant. Though no statistical diffidence was seen in marital status as a whole, status of separation and widowhood were more among females (statistical analysis with combined because of small number of cases). More females were from far places than males. More males were educated among problem drinkers.

\section{Acknowledgements}

Prof. Biswajit Sen (late) and Prof. PM Shyangwa for valuable suggestion/ input during the inception of this study, and Mr. Gayanand Mandal, College of Nursing, BPKIHS for statistical assistance.

\section{Conflict of interest}

The author declares no conflict of interest.

\section{References}

1. WHO. Global Status Report on Alcohol, Geneva, 2004.

2. Murray, Lopez. The Global Burden of Disease: A Comprehensive Assessment of Mortality and Disability from Diseases, Injuries, and Risk Factors in 1990 and Projected 2020. Boston, Harvard School of Public Health on behalf of the World Health Organization and World Bank, USA, 1996.

3. Shrestha DM, Shrestha BK. Tobacco and Alcohol use in Nepal. Paper presented at the WHO Regional Consultation on Tobacco and Alcohol, Srilanka, 1997.

4. Shakya DR. Alcohol abuse in eastern Nepal: a review of studies. Health Renaissance. 2013;11(1):74-82.

5. Shakya DR, Shyangwa PM, Sen B. A study of socio-demographic profile, psychiatric co-morbidities and help seeking behavior in ADS attending BPKIHS, Nepal. MD thesis. 2005.

6. Shakya DR, Shyangwa PM, Shakya R. Psychiatric emergencies in a Tertiary care Hospital. JNMA J Nepal Med Assoc. 2008;47(169):28-33.

7. Shakya DR, Pandey AK, Shyangwa PM, et al. Psychiatric morbidity profiles of referred Psychiatry OPD patients in a general hospital. Indian Med. 2009;103:407-11.

8. Gautam R, Shyangwa P, Shakya DR, et al. Female patients with Alcohol related problems: Clinical profile, Co-morbidity and their Attitude. MD thesis. 2010 .

9. Bond JC, Roberts SCM, Greenfield TK, et al. Gender Differences in Public and Private Drinking Contexts: A Multi-Level GENACIS Analysis. Int J Environ Res Public Health. 2010;7(5):2136-2160.

10. Wilsnack RW, Wilsnack CS. Gender and alcohol: Consumption and consequences. 1st ed. In: Boyle P, Boffetta P, et al. editors. Alcohol: Science, Policy, and Public Health. USA: Oxford University Press; 2013. p. $153-160$

11. World Health Organization (WHO). Gender, Health and Alcohol use. Geneva: WHO Department of Gender, Women and Health, Switzerland, 2005.

12. Shakya DR, Shyangwa PM, Sen B. Physical Diseases in Cases Admitted for Alcohol Dependence. Health Renaissance. 2008;5(1):27-31.

13. Shakya DR, Shyangwa PM, Sen B. Psychiatric co-morbidity in Cases Admitted for Alcohol Dependence. Delhi Journal of Psychiatry. 2009;12(2):252-257.

14. Shakya DR, Shyangwa PM, Sen B. Help seeking behaviour in patients with alcohol dependence in a tertiary care hospital in eastern Nepal. Journal of Psychiatrists' Association of Nepal. 2011;1(1):15-19.

15. World Health Organization. The ICD-10 Classification of Mental and Behavioral Disorders Diagnostic Criteria for Research. WHO, Geneva, Switzerland, 1993.

16. Jhingan HP, Sharma A, Koirala S, et al. Prevalence of alcohol dependence in a town in Nepal as assessed by CAGE questionnaire. Addiction. 2003;98(3):339-343.

17. Niraula SR, Shyangwa PM, Jha N. Alcohol use among women in a town of eastern Nepal. J Nepal Med Assoc. 2004;43:244-249. 
18. Schuckit MA. Alcohol Related Disorders. 9th ed. In: Sadock BJ, Sadock VA and Ruiz P, Editors. Comprehensive Textbook of Psychiatry, Philadelphia: Wolter Kluwer, Lippincott. USA: Williams and Wilkins, 2009. p. 1269-1288

19. Royal College of Psychiatrists. A Historical Perspective. Alcohol: Our Favorite Drug. Tavistock, London, 1986. 11 p.
20. Shakya DR. Circumstances of the first drink among Problem drinkers seeking help from a Psychiatric service of a Teaching institute in eastern Nepal. J Health Renaissance. 2014;12(3):154-161.

21. WHO Gender disparities in mental health. 2016 